Karlsruhe Institute of Technology

08. Mar. 2016

\begin{tabular}{|c|c|}
\hline Title: & An Ultra-Efficient Maximum Power Point Tracking Circuit for Photovoltaic Inverters \\
\hline Authors: & Mario Gommeringer, Alexander Schmitt, Felix Kammerer, Michael Braun \\
\hline Institute: & $\begin{array}{l}\text { Karlsruhe Institute of Technology (KIT) } \\
\text { Elektrotechnisches Institut (ETI) }\end{array}$ \\
\hline Type: & Conference Proceedings \\
\hline Published at: & $\begin{array}{ll}\text { IECON 2015 - 41st Annual Conference of the IEEE Industrial Electronics Society } \\
\begin{array}{ll}\text { Date of Conference: } & \text { 09. Nov. } 2015-12 . \text { Nov. } 2015 \\
\text { Page(s): } & 001704-001709 \\
\text { Conference Location: } & \text { Yokohama, Japan } \\
\text { Publisher: } & \text { IEEE } \\
\text { ISBN: } & 978-1-4799-1762-4\end{array}\end{array}$ \\
\hline Links: & DOI: 10.1109/IECON.2015.7392347 \\
\hline
\end{tabular}

(C) 2015 IEEE. Personal use of this material is permitted. Permission from IEEE must be obtained for all other uses, in any current or future media, including reprinting/republishing this material for advertising or promotional purposes, creating new collective works, for resale or redistribution to servers or lists, or reuse of any copyrighted component of this work in other works. 


\title{
An Ultra-Efficient Maximum Power Point Tracking Circuit for Photovoltaic Inverters
}

\author{
Mario Gommeringer, Alexander Schmitt, Felix Kammerer, Michael Braun \\ Elektrotechnisches Institut (ETI) - Electrical Drives and Power Electronics \\ Karlsruhe Institute of Technology (KIT) \\ Kaiserstr. 12, 76131 Karlsruhe, Germany \\ Email: mario.gommeringer@kit.edu
}

\begin{abstract}
This paper deals with a new ultra-efficient circuit for the individual maximum power point (MPP) tracking of an unlimited number of photovoltaic strings. The circuit generates a DC output voltage and can be combined with common DC-AC solar inverter circuits. The necessary blocking voltages of the transistors are far below the maximum string voltages, which yields to low losses and small passive components. An appropriate controller structure is developed and a prototype is built up, that reaches a maximum efficiency of 99.85 percent
\end{abstract}

Keywords-DC-DC power converters; Maximum power point trackers

\section{INTRODUCTION}

Large photovoltaic installations are often built up with central inverters that are fed by several strings. If the DC lines are combined with string diodes or fuses [1], every string runs at the same voltage and partial shading can lead to a significant power loss of the affected string. The usage of multiple boost converters or electrically isolated converters [2] at the DC-side allows an individual MPP-tracking of every string but causes additional costs and losses. Further solutions are multipleinput-single-inductor buck converters [3], multiple-inputsingle-inductor buck-boost converters $[4,5]$ or multiple-input flyback converters [5].

Indeed, a converter input voltage range down to $0 \mathrm{~V}$ is usually not necessary for a reasonable operation. Fig. 1 shows exemplary power curves of three strings with the same electrical configuration. One of them is unshaded and two are partially shaded. Assuming, that the strings are combined with a three-input DC-DC converter, an input voltage range that reaches from $u_{\mathrm{G} \text {,min }}$ to $u_{\mathrm{G}, \max }$ is absolutely sufficient to operate all strings at their MPP.

This paper investigates a new circuit (Fig. 2), which is basically described in [6]. In this circuit, the switched voltages are reduced to about $u_{\mathrm{G}, \max }-u_{\mathrm{G} \text {,min }}$. This leads to very low losses and small passive components. Additionally, the circuit allows the buffering of $100 \mathrm{~Hz} / 120 \mathrm{~Hz}$ components at the DCside, when a single-phase inverter is connected [6].

Another circuit with similar function is described in [7]. The voltages that have to be switched in that circuit are also below the maximum string voltage $u_{\mathrm{G}, \max }$ at its MPP, but not as low as in the proposed circuit of Fig. 2.
The proposed circuit contains $N$ input half-bridges that are built up with two MOSFETs T1x and T2x $(x \in\{1 \ldots N\})$. Furthermore, every input needs a capacitor $\mathrm{C} 4 x$ and an inductor L1x. The MOSFETs T3 and T4 of the output half-bridge, as well as the capacitor $\mathrm{C} 1$, are only needed once. The input voltages $u_{\mathrm{G} x}$ can be controlled in the range $\bar{u}_{\mathrm{H}} \leq u_{\mathrm{G} x} \leq \bar{u}_{\mathrm{H}}+u_{\mathrm{C} 1}$, where $\bar{u}_{\mathrm{H}}$ is the mean value of the pulsed voltage $u_{\mathrm{H}}$ during one pulse-period. $\bar{u}_{\mathrm{H}}$ can be chosen freely, what allows a movement of the voltage range, that is marked gray in Fig. 1. An inverter that is connected between the terminals $\mathrm{A}+$ and $\mathrm{A}-$ is fed by the circuit with a DC voltage $u_{\mathrm{A}}$. Neglecting losses, the mean value of the voltage $u_{\mathrm{A}}$ is always between the lowest string voltage $u_{\mathrm{G}, \min }$ and the highest string voltage $u_{\mathrm{G}, \max }$.

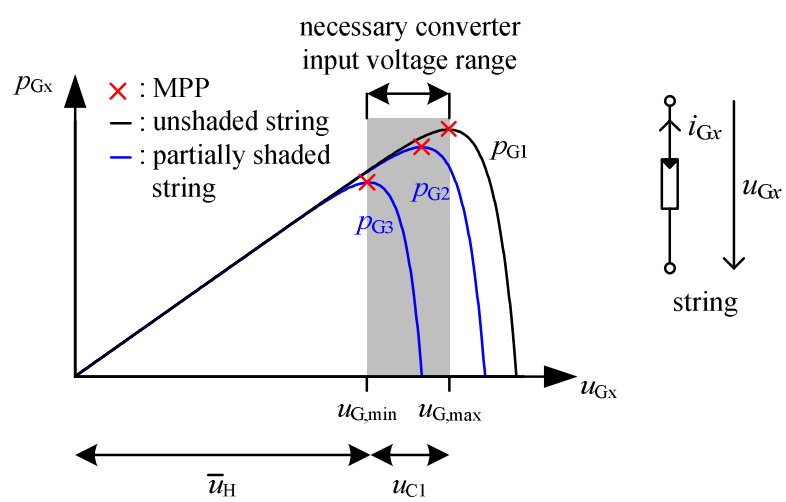

Fig. 1. Power of unshaded and partially shaded strings and necessary converter input voltage range; Model parameters are taken from Table 2 of [8]

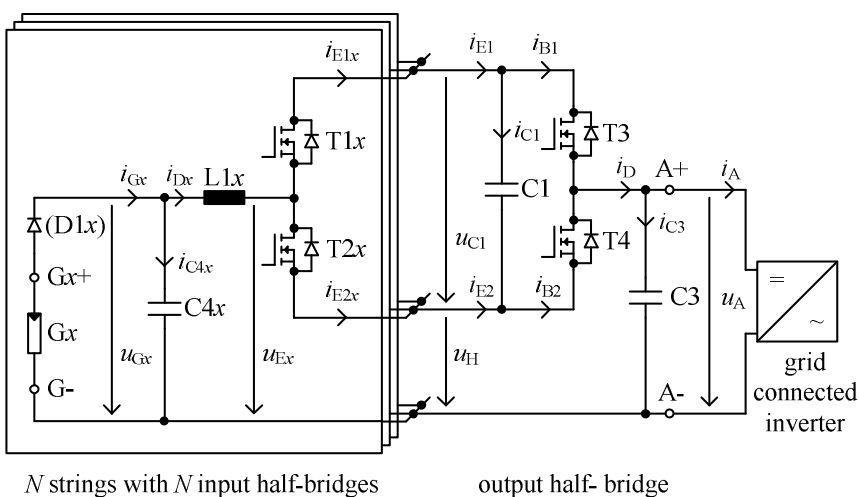

Fig. 2. The new MPP tracking circuit (see also [6]) 
The circuit is compared with conventional boost converters in Section II and described in detail in Section III. A cascaded control scheme is developed in Section IV. Prototype measurements show the proper function and the very high efficiency in Section V.

\section{COMPARISON WITH CONVENTIONAL BOOST CONVERTERS}

The total switched power $P_{\mathrm{sw}}$ of the proposed circuit (Fig. 2) is calculated with equation (1) by summing the products of drain-source voltage and drain current of every transistor. The inductor currents $i_{\mathrm{D} x}$ are assumed as DC currents without ripple and $i_{\mathrm{G}, \max }$ is the maximum expected current of the strings. The voltage at the capacitor $\mathrm{C} 1$ is set to $u_{\mathrm{C} 1}=u_{\mathrm{G}, \max }-u_{\mathrm{G}, \min }$.

$$
P_{\mathrm{sW}, \mathrm{MPPTC}}=N \cdot 4 \cdot\left(u_{\mathrm{G}, \max }-u_{\mathrm{G}, \min }\right) \cdot i_{\mathrm{G}, \max }
$$

The proposed circuit is now compared to a conventional solution with boost converters for the individual control of $N$ string voltages (Fig. 3).

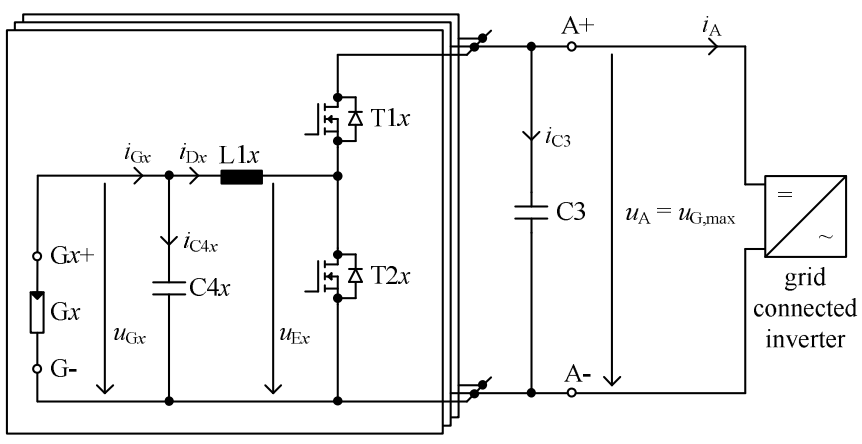

Fig. 3. Conventional solution with boost converters

The total switched power of the conventional circuit (Fig. 3) is given by the following equation:

$$
P_{\text {sw,boost }}=N \cdot 2 \cdot u_{\mathrm{G}, \max } \cdot i_{\mathrm{G}, \max }
$$

A low value of $P_{\mathrm{sw}}$ usually leads to low losses and low semiconductor costs. As long as the difference $u_{\mathrm{G}, \max }-u_{\mathrm{G}, \min }$ is smaller than $50 \%$ of $u_{\mathrm{G}, \max }$, the total switched power of the proposed MPP tracking circuit is lower than the total switched power of the conventional circuit with boost converters. This condition is usually fulfilled in photovoltaic applications.

\section{FUNCTION OF THE NEW MPP TRACKING CIRCUIT}

The transistors T $1 x$ and T $2 x$ (Fig. 2) are controlled by a pulse width modulation (PWM) with a duty cycle of $a_{\mathrm{D} x}$ and a switching frequency of $f_{\text {sw }}$ :

$$
T_{\mathrm{T} 1 x}=a_{\mathrm{D} x} \cdot \frac{1}{f_{s w}} \quad \mid \quad T_{\mathrm{T} 2 x}=\left(1-a_{\mathrm{D} x}\right) \cdot \frac{1}{f_{s w}}
$$

The input current $i_{\mathrm{G} x}$ of each half-bridge is split into the currents $i_{\mathrm{E} 1 x}$ and $i_{\mathrm{E} 2 x}$ by T1x and T2x. Their mean values during one pulse-period are:

$$
\bar{i}_{\mathrm{E} 1 x}=a_{\mathrm{D} x} \cdot i_{\mathrm{G} x} \quad \mid \quad \bar{i}_{\mathrm{E} 2 x}=\left(1-a_{\mathrm{D} x}\right) \cdot i_{\mathrm{G} x}
$$

All $N$ input half-bridges can be modeled as one equivalent input half-bridge according to Fig. 4 with the equivalent voltage $u_{\mathrm{G}}$ and the equivalent currents $i_{\mathrm{G}}$ and $i_{\mathrm{D}}$. These values are needed later in the control system. The current $i_{\mathrm{G}}$ is the sum of all input currents $i_{\mathrm{Gx}}$, while $i_{\mathrm{D}}$ is the sum of all inductor currents $i_{\mathrm{D} x}$.

$$
i_{\mathrm{G}}=\sum_{x=1}^{N} i_{\mathrm{G} x} \quad \mid \quad i_{\mathrm{D}}=\sum_{x=1}^{N} i_{\mathrm{D} x}
$$

The equivalent voltage $u_{\mathrm{G}}$, which is always between the lowest string voltage $u_{\mathrm{G}, \min }$ and the highest string voltage $u_{\mathrm{G}, \max }$, is determined with the assumption that all powers $p_{\mathrm{G} x}=u_{\mathrm{G} x} \cdot i_{\mathrm{G} x}$ sum up to the equivalent power $p_{\mathrm{G}}=u_{\mathrm{G}} \cdot i_{\mathrm{G}}$ :

$$
u_{\mathrm{G}}=\frac{p_{\mathrm{G}}}{i_{\mathrm{G}}}=\frac{\sum_{x=1}^{N} p_{\mathrm{G} x}}{i_{\mathrm{G}}}=\frac{\sum_{x=1}^{N} u_{\mathrm{G} x} \cdot i_{\mathrm{G} x}}{i_{\mathrm{G}}}
$$

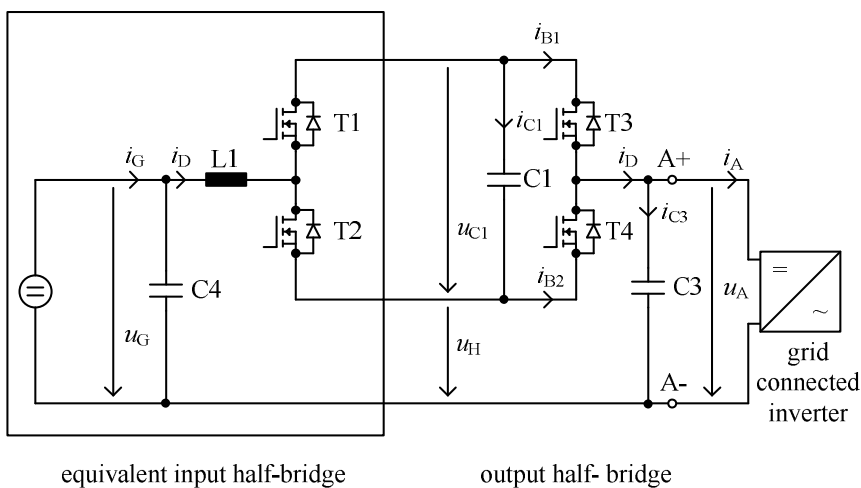

Fig. 4. Equivalent circuit with equivalent input half-bridge

The currents $i_{\mathrm{B} 1}$ and $i_{\mathrm{B} 2}$ are combined by the output halfbridge, consisting of $\mathrm{T} 3$ and T4. The two MOSFETs are controlled by a PWM modulation with the duty cycle $a_{\mathrm{F}}$ :

$$
T_{\mathrm{T} 3}=a_{\mathrm{F}} \cdot \frac{1}{f_{s w}} \quad \mid \quad T_{\mathrm{T} 4}=\left(1-a_{\mathrm{F}}\right) \cdot \frac{1}{f_{s w}}
$$

In stationary operation, the mean output power $\bar{p}_{\mathrm{F}}=u_{\mathrm{A}} \cdot \overline{i_{\mathrm{D}}}$ is the input power $p_{\mathrm{G}}=u_{\mathrm{G}} \cdot i_{\mathrm{G}}$ minus the circuit losses. The output current $i_{\mathrm{A}}$ equals the mean value of $i_{\mathrm{D}}$ and equals $i_{\mathrm{G}}$. Therefore, the output voltage $u_{\mathrm{A}}$ is approximately $u_{\mathrm{G}}$.

$$
i_{\mathrm{A}}=\bar{i}_{\mathrm{D}}=i_{G} \quad \mid \quad u_{\mathrm{A}} \approx u_{\mathrm{G}}
$$

As consequence, the inverter is fed with a voltage $u_{\mathrm{A}}$, that can vary approximately between the lowest string voltage $u_{\mathrm{G}, \min }$ and the highest string voltage $u_{\mathrm{G}, \max }$. Boosting above $u_{\mathrm{G}, \max }$ is not possible. This is no disadvantage, as most inverter topologies can be operated with variable DC input voltages.

The voltage $u_{\mathrm{C} 1}$ can be controlled to approximately $u_{\mathrm{G}, \max }-u_{\mathrm{G}, \min }$ when the circuit is operating. This leads to low switching losses at T1 $x$ - T4 due to the low switched voltages [9] and to small inductors L1x.

Basically, the semiconductors T1x - T4 and the capacitor $\mathrm{C} 1$ can be dimensioned for lower voltages than the maximum 
expectable string voltages [6]. This allows the usage of fastswitching MOSFETs with very low $R_{\mathrm{DS}(\text { on) }}$. Furthermore, semiconductors with lower blocking voltage and same current capability are often cheaper than types with higher blocking voltage. However, measures against overvoltage of $u_{\mathrm{C} 1}$ have to be taken in this case. When the strings are connected between $\mathrm{G} x+$ and $\mathrm{A}-$ before the control system is active, $\mathrm{C} 1$ and $\mathrm{C} 3$ act as capacitive voltage divider. Therefore, the ratio of $\mathrm{C} 1$ and $\mathrm{C} 3$ has to be chosen considering the maximum voltage $u_{\mathrm{C} 1}$. The control system of the inverter can be supplied directly from the strings ( $\mathrm{G} x+/ \mathrm{G}-)$ and not from $\mathrm{A}+/ \mathrm{A}$ - to prevent $\mathrm{C} 1$ from charging by discharging C3. Alternatively, T2x or T3 could be realized as depletion MOSFETs that are conducting as long as the control system is not active. If external short circuits between $\mathrm{G} x+$ and G- can occur, measures against negative currents $i_{\mathrm{G} x}$ have to be taken. This can be done e.g. by string interrupting relays or diodes D1x. Since only DC currents are flowing through D1x, cheap and slow rectifier diodes with low forward voltage are advantageous.

The semiconductors $\mathrm{T} 1 x-\mathrm{T} 4$ and $\mathrm{C} 1$ can also be dimensioned for the maximum expectable string voltages. In this case, no additional measures against overvoltage of $u_{\mathrm{C} 1}$ are needed. Nevertheless, the voltage $u_{\mathrm{C} 1}$ can be controlled to approximately $u_{\mathrm{G}, \max }-u_{\mathrm{G}, \min }$ when the circuit is operating, which is advantageous for low switching losses and small inductors L1 $\mathrm{x}$.

Additionally, the circuit is capable of buffering pulsating energy, which occurs when a single-phase inverter is connected. The input voltages $u_{\mathrm{G} x}$ can be held constant, while a high voltage ripple on $u_{\mathrm{A}}$ is permissible. This allows the use of a small film capacitor $\mathrm{C} 3$ with long lifetime. The voltage $u_{\mathrm{A}}$ can temporarily exceed $u_{\mathrm{G}, \min }$ and $u_{\mathrm{G}, \max }$ if $u_{\mathrm{C} 1}$ is chosen higher than $u_{\mathrm{G}, \max }-u_{\mathrm{G}, \min }$.

\section{CASCADED CONTROL SCHEME}

A cascaded control scheme has been developed for the MPP tracking circuit. The circuit contains $2 N+2$ components that store energy:

- $\quad N$ capacitors $\mathrm{C} 4 x$

- $\quad N$ inductors L $1 x$

- Capacitor $\mathrm{C} 1$

- Capacitor C3

For control purposes, the following values need to be measured:

- $\quad N$ input voltages $u_{\mathrm{G} x}$

- $\quad N$ inductor currents $i_{\mathrm{D} x}$

- Capacitor voltage $u_{\mathrm{C} 1}$

- $\quad$ Output voltage $u_{\mathrm{A}}$

The cascaded control scheme requires the following reference values:

- $\quad N$ input reference voltages $u_{\mathrm{G} x, \mathrm{w}}$

- $\quad$ Reference capacitor voltage $u_{\mathrm{C} 1, \mathrm{w}}$
The currents $i_{\mathrm{Dx}}$ of the inductors L1x are set with $N$ inner current controllers. The currents $i_{\mathrm{D} x}$ are used to control the $N$ string voltages $u_{\mathrm{G} x}$ in an outer voltage control loop. The output voltage $u_{\mathrm{A}}$ is controlled with the active power component of the inverter. Last, the capacitor voltage $u_{\mathrm{C} 1}$ is controlled by an outer voltage control loop, which uses the output voltage $u_{\mathrm{A}}$ as degree of freedom. The $N$ inner control loops for the currents $i_{\mathrm{D} x}$ are shown in Fig. 5. Values that occur physically are drawn in blue. Values that occur in the control system are drawn in red and marked with '. All values are mean values during one pulse-period.

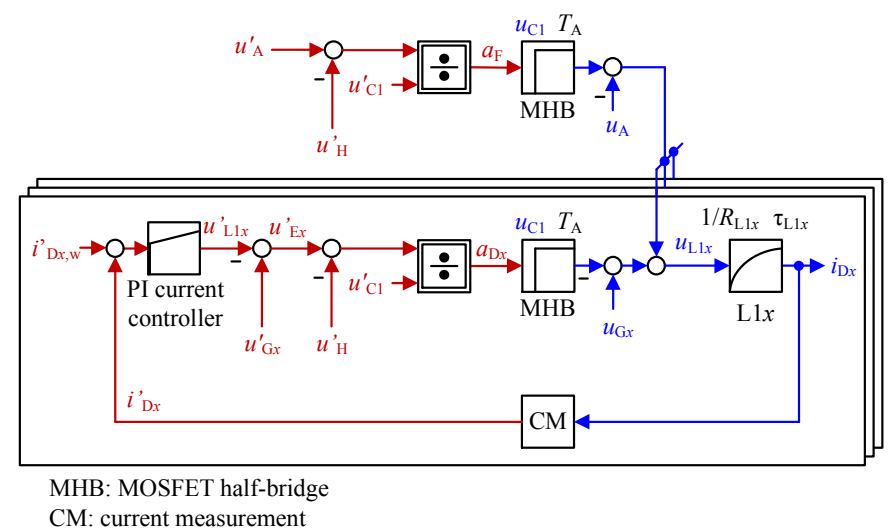

Fig. 5. Inner current control structure for $i_{\mathrm{Dx}}$

The $N$ inductors L1 $x$ are modeled as first order lag element, which allows the consideration of a series resistance $R_{\mathrm{L} 1 x}$. The voltages $u_{\mathrm{L} 1 x}$ at the inductors L1 $x$ are given by:

$$
u_{\mathrm{L} 1 x}=u_{\mathrm{G} x}-a_{\mathrm{D} x} \cdot u_{\mathrm{C} 1}+a_{\mathrm{F}} \cdot u_{\mathrm{C} 1}-u_{\mathrm{A}}
$$

The upper part of Fig. 5 calculates the duty cycle $a_{\mathrm{F}}$ for the output half-bridge and is only needed once. $a_{\mathrm{F}}$ depends on the reference value $u_{\mathrm{H}}$, which equals the mean value $\bar{u}_{\mathrm{H}}$ of $u_{\mathrm{H}}$. The condition $u_{\mathrm{H}}^{\prime} \leq u_{\mathrm{G} \text {,min }}$ has to be maintained when $u_{\mathrm{H}}^{\prime}$ is chosen. The $N$ output values $u_{\mathrm{L} 1 x}$ of the current controllers influence the duty cycles $a_{\mathrm{Dx}}$. The values $u_{\mathrm{Gx}}, u_{\mathrm{C} 1}$ and $u_{\mathrm{A}}$ are measured and fed-forward. A delay time of $T_{\mathrm{A}}$ is caused by the calculations in the control system.

Standard PI current controllers are usually sufficient for three phase inverters. For higher dynamic requirements or single phase inverters with pulsating voltages $u_{\mathrm{A}}$, state controllers according to Fig. $6[10,11]$ are advantageous. Measures against wind-up have to be considered in all controllers with integrating component.

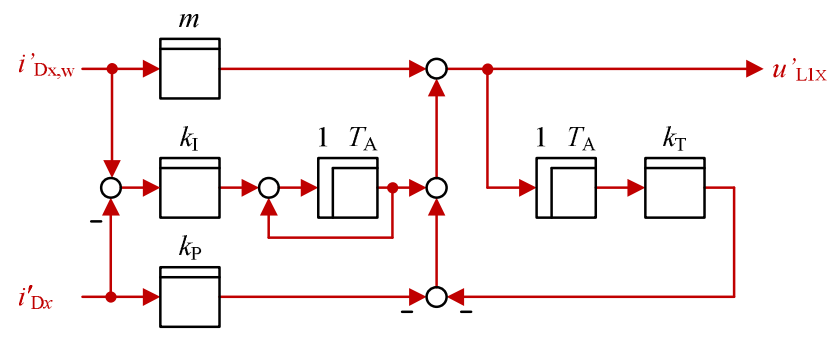

Fig. 6. Current state controller with integrating component for $i_{\mathrm{Dx}}[10,11]$; simplified diagram; parameters can be found in [11] 
The string voltages $u_{\mathrm{G} x}$, which occur at the capacitors $\mathrm{C} 4 x$ are controlled with $N$ outer voltage controllers according to Fig. 7. The capacitor currents $i_{\mathrm{C} 4 x}$ are given by:

$$
i_{\mathrm{C} 4 x}=i_{\mathrm{G} x}-i_{\mathrm{D} x}
$$

As the input currents $i_{\mathrm{G} x}$ are not measured, they cannot be fed forward. This leads to PI voltage controllers.

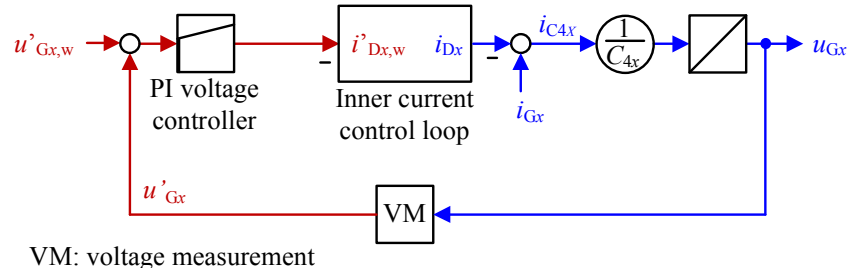

Fig. 7. Outer voltage control structure for $u_{\mathrm{Gx}}$

The PI voltage controllers are fed with reference values $u_{\mathrm{G} x, \mathrm{w}}$ from standard MPP tracking algorithms (Fig. 8, e.g. perturb and observe algorithms).

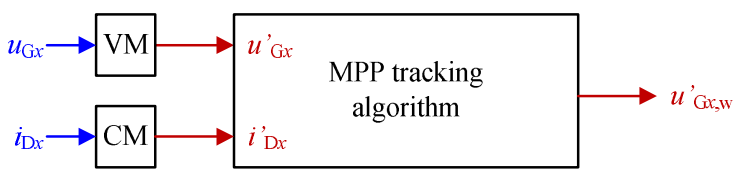

Fig. 8. MPP tracking algorithm

The output voltage $u_{\mathrm{A}}$ is controlled with the active power component, delivered to the grid by the inverter. An appropriate controller structure is shown in Fig. 9. The reference value $i_{\mathrm{A}, \mathrm{w}}$ of the $\mathrm{DC}$ current $i_{\mathrm{A}}$ is used within the inverter for the control of the active $\mathrm{AC}$ current at the output. The value $i_{\mathrm{D}, \mathrm{w}}$ can be calculated with (11) and fed forward. Single-phase inverters lead to a voltage ripple on $u_{\mathrm{A}}$ with double output frequency. An optional moving-average filter with an averaging time of $T_{\text {avg }}=1 /\left(2 \cdot f_{\text {grid }}\right)$ suppresses this ripple.

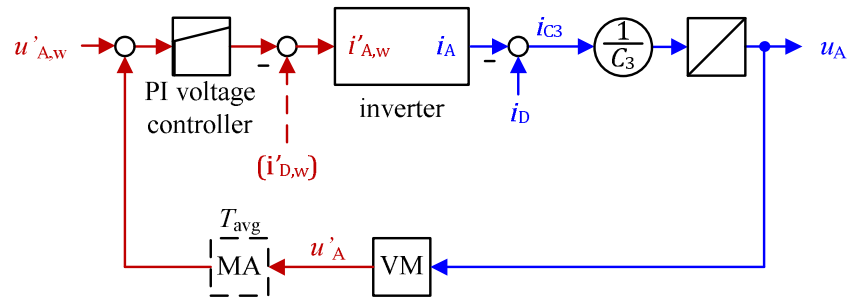

MA: moving average filter

Fig. 9. Control structure for $u_{\mathrm{A}}$

$$
i_{\mathrm{D}, w}^{\prime}=\sum_{x=1}^{N} i_{\mathrm{D} x, \mathrm{w}}^{\prime}
$$

Last, the capacitor voltage $u_{\mathrm{C} 1}$ has to be controlled. The sum power $p_{\mathrm{D}}$ at the input of the MPP tracking circuit is given by:

$$
p_{\mathrm{D}}=u_{\mathrm{G}} \cdot i_{D}
$$

The power $p_{\mathrm{F}}$ at the output of the circuit is:

$$
p_{\mathrm{F}}=u_{\mathrm{A}} \cdot i_{D}
$$

Neglecting losses, the difference of these powers occurs at the capacitor $\mathrm{C} 1$ :

$$
p_{\mathrm{C} 1}=p_{\mathrm{D}}-p_{\mathrm{F}}
$$

The capacitor current $i_{\mathrm{C} 1}$ and therefore $p_{\mathrm{C} 1}$ have to be zero at stationary operation:

$$
u_{\mathrm{C} 1}=\frac{1}{C_{1}} \int i_{\mathrm{C} 1} \mathrm{~d} t=\frac{1}{C_{1}} \int \frac{p_{\mathrm{C} 1}}{u_{\mathrm{C} 1}} \mathrm{~d} t
$$

The output voltage $u_{\mathrm{A}}$ is a degree of freedom and can be used to control $u_{\mathrm{C} 1}$. An appropriate control structure is shown in Fig. 10.

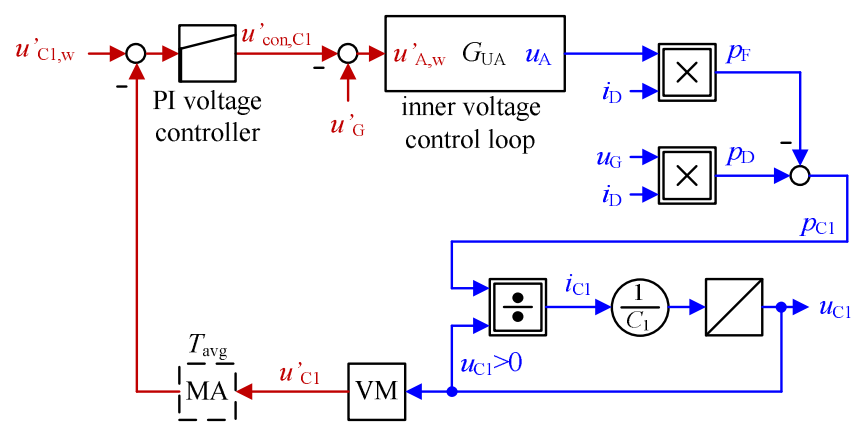

Fig. 10. Outer voltage control structure for $u_{\mathrm{C} 1}$

The power $p_{\mathrm{C} 1}$ can be expressed by:

$$
p_{\mathrm{C} 1}=\underbrace{u_{\mathrm{G}} \cdot i_{\mathrm{D}}}_{p_{\mathrm{D}}}+\underbrace{G_{\mathrm{UA}} \cdot u_{\text {con, } \mathrm{C} 1}^{\prime} \cdot i_{\mathrm{D}}-G_{\mathrm{UA}} \cdot u_{\mathrm{G}}^{\prime} \cdot i_{\mathrm{D}}}_{-p_{\mathrm{F}}}
$$

Here, $G_{\mathrm{UA}}=u_{\mathrm{A}} / u_{\mathrm{A}, \mathrm{w}}$ describes the behavior of the inner voltage control loop. The Laplace-transformed transfer function from the controller output $u_{\text {con, } \mathrm{C} 1}$ to the voltage $u_{\mathrm{C} 1}$ is as follows:

$$
\frac{u_{\mathrm{C} 1}(s)}{u^{\prime}{ }_{\mathrm{con}, \mathrm{C} 1}(s)}=G_{\mathrm{UA}}(s) \cdot \frac{i_{\mathrm{D}}}{u_{\mathrm{C} 1}} \cdot \frac{1}{C_{1}} \cdot \frac{1}{s}
$$

The gain of the transfer function depends on $i_{\mathrm{D}}$ and $u_{\mathrm{C} 1}$. This has to be considered, when controller parameters are calculated. Single-phase inverters lead to a voltage ripple on $u_{\mathrm{C} 1}$ with double output frequency, which can be suppressed by a moving average filter in the measuring path. The voltage $u_{\mathrm{C} 1}$ can be changed dynamically during operation and should be kept as low as possible to minimize the switching losses.

\section{EXPERIMENTAL RESULTS}

A prototype for three strings has been built up to verify the function of the MPP tracking circuit. Fig. 11a shows one of two identical printed circuit boards with two MOSFET halfbridges. The circuit feeds a single-phase IGBT H-bridge inverter, shown in Fig. 11b. Values and part names of 
important components are listed in Table I. The maximum output current is $25 \mathrm{~A}$, the switching frequency of T1x-T4 has been set to $16 \mathrm{kHz}$. a)

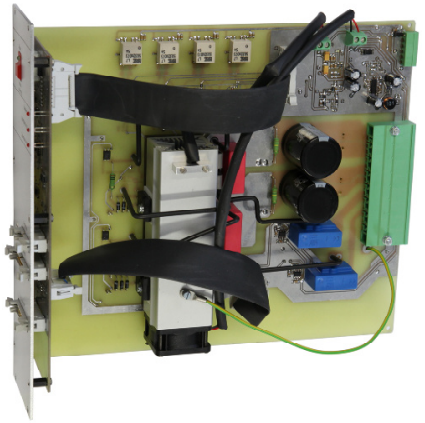

b)

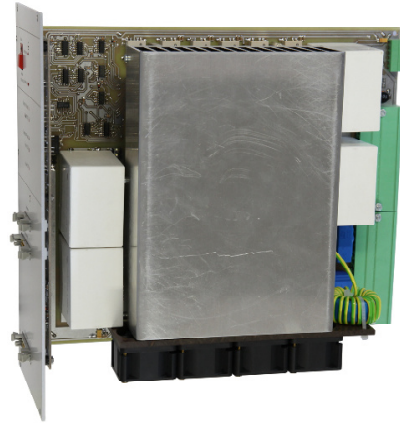

Fig. 11. Prototype printed circuit boards

TABLE I. COMPONENT VALUES AND NAMES

\begin{tabular}{|l|l|}
\hline \multicolumn{1}{|c|}{ Part } & \multicolumn{1}{c|}{ Value / Part Name } \\
\hline $\mathrm{C} 1$ & $8800 \mu \mathrm{F} / 160 \mathrm{~V}$ electrolytic capacitors \\
\hline $\mathrm{C} 3$ & $\begin{array}{l}500 \mu \mathrm{F} / 900 \mathrm{~V} \text { film capacitors (MPP tracking circuit }+ \\
\text { inverter) }\end{array}$ \\
\hline $\mathrm{C} 4 x$ & $50 \mu \mathrm{F} / 900 \mathrm{~V}$ film capacitor \\
\hline $\mathrm{L} 1 \mathrm{x}$ & $1.9 \mathrm{mH}$ \\
\hline $\mathrm{D} 1 x$ & not used; string relays are used instead \\
\hline $\mathrm{T} 1 \mathrm{x}-\mathrm{T} 4$ & Infineon IPP110N20N3 (200V / 10.7m $\Omega)$ \\
\hline
\end{tabular}

\section{A. Operation}

Measurements have been performed with three strings of "MQ36" photovoltaic panels, see Fig. 12. The individual string voltages $u_{\mathrm{G} x}$ are set to different values. The currents $i_{\mathrm{D} x}$ are

a)

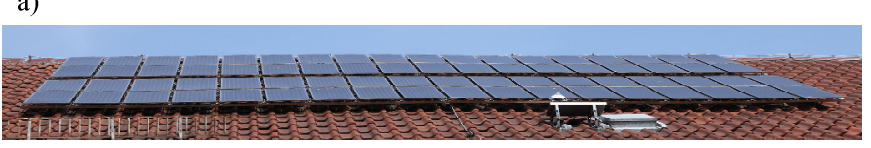

b)

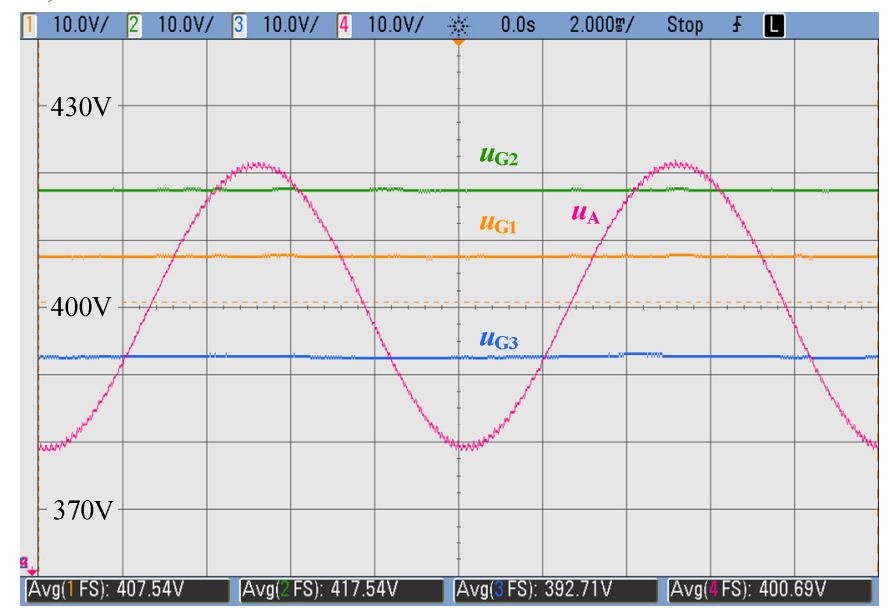

Fig. 12. a) Photovoltaic panels (three strings)

b) Experimental results: string voltages $u_{\mathrm{G} x}$ and output voltage $u_{\mathrm{A}}$ controlled with state controllers according to Fig. 6. As the single-phase inverter sinks a pulsating power with double gridfrequency at its DC-side, the voltage $u_{\mathrm{A}}$ is pulsating with $100 \mathrm{~Hz}$. The pulsating energy is buffered in $\mathrm{C} 1$ and $\mathrm{C} 3$. The output capacitor $\mathrm{C} 3$ is realized as film capacitor with only $500 \mu \mathrm{F}$. The voltage ripple $\Delta u_{\mathrm{A}}$ is $42 \mathrm{~V}$ at a DC power of $p_{\mathrm{D}}=2.7 \mathrm{~kW}$ and a grid frequency of $f_{\text {grid }}=50 \mathrm{~Hz}$.

When solar panels are connected directly to a single-phase inverter with $100 \mathrm{~Hz}$ input voltage ripple, the operating point on the power curve (Fig. 1) moves around the MPP with the same frequency. This reduces the mean power, delivered by the panels. The MPP tracking circuit holds the string voltages $u_{\mathrm{G} x}$ constant (Fig. 12), which increases the mean power of the solar panels.

\section{B. Efficiency}

Efficiency measurements usually lead to relatively high tolerances when the measured output power of a circuit is divided by the measured input power $\left(\eta=p_{\text {out }} / p_{\text {in }}\right)$. Therefore, a special measurement setup according to Fig. 13 is used, that leads to more accurate results due to lower voltage measuring ranges of the used power analyzer.

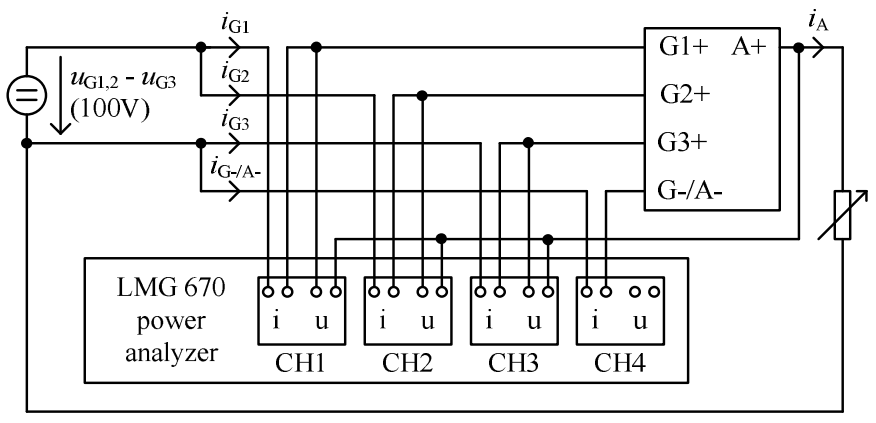

Fig. 13. Efficiency measurement setup

The DC-currents at the capacitors C4x and C3 (Fig. 2) are zero at stationary operation, so the DC-current $i_{\mathrm{G}-/ \mathrm{A}-}$ at the terminal G-/A- (Fig. 13) is also zero. Therefore, the losses depend on the voltage differences between $u_{\mathrm{G} 1} . . u_{\mathrm{G} 3}$ and on the currents $i_{\mathrm{G} x}$, but not on the absolute values of $u_{\mathrm{G} x}$, that occur between the terminals $\mathrm{G} x+$ and G-.

Below, the efficiency of the circuit is investigated for the following operating condition: two strings G1 and G2 are operated with a higher voltage $u_{\mathrm{G} 1}=u_{\mathrm{G} 2}=u_{\mathrm{G} 1,2}$ and one string $\mathrm{G} 3$ is operated with a lower voltage $u_{\mathrm{G} 3}$ of $u_{\mathrm{G} 3}=u_{\mathrm{G} 1,2}-100 \mathrm{~V}$. All string currents are equal $\left(i_{\mathrm{G} 1}=i_{\mathrm{G} 2}=i_{\mathrm{G} 3}\right)$.

The voltage $u_{\mathrm{G} 1,2}-u_{\mathrm{G} 3}=100 \mathrm{~V}$ is provided by a laboratory power supply (Fig. 13). Terminal G-/A- is connected to G3+. The output current $i_{\mathrm{A}}$ is set by a resistor. The control system, which is powered externally, ensures that all currents $i_{\mathrm{G} x}$ are one third of $i_{\mathrm{A}}$. The capacitor voltage $u_{\mathrm{C} 1}$ is set to $110 \mathrm{~V}$ and the voltage $u_{\mathrm{H}}$ is set to $-5 \mathrm{~V}$. This ensures, that all transistors $\mathrm{T} 1 x-$ T4 are switching with $16 \mathrm{kHz}$. The losses $p_{\mathrm{V}}$ of the circuit are calculated by adding the three powers $p_{\mathrm{CH} 1} . . p_{\mathrm{CH} 3}$, that are measured by a LMG670 precision power analyzer from ZES Zimmer. 
The fourth channel is used to verify that no DC current occurs at the terminal G-/A-. The losses $p_{\mathrm{V}}$ are plotted in Fig. 14 at different output currents $i_{\mathrm{A}} . p_{\mathrm{V}}$ contains no losses in relays, gate-units, discharging resistors and in the control system. No diodes D1 $x$ are used. The maximum uncertainty $\Delta p_{\mathrm{V}}=\Delta p_{\mathrm{CH} 1}+\Delta p_{\mathrm{CH} 2}+\Delta p_{\mathrm{CH} 3}$ of the LMG 670 power analyzer is calculated according to [12] and plotted with dashed lines. Typical uncertainties of the LMG670 are usually about 2..5 times below the calculated maximum uncertainties [12].

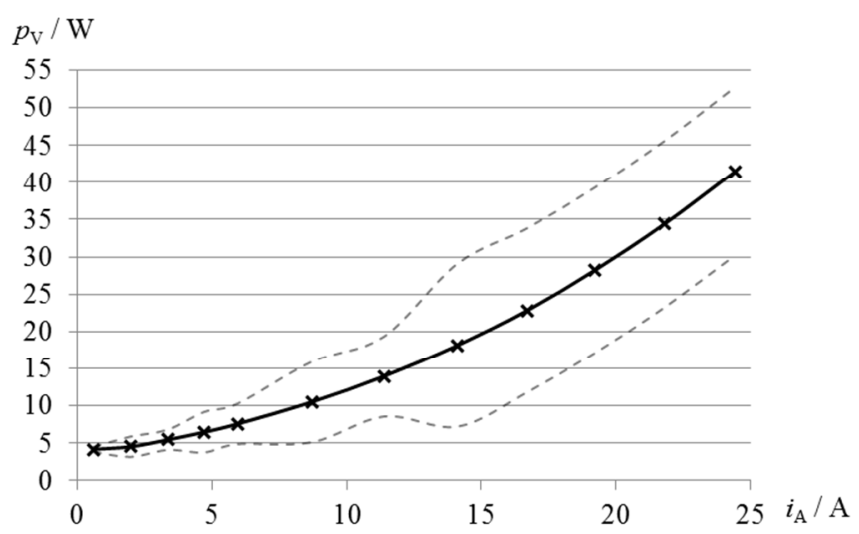

Fig. 14. Measured losses; lines interpolated; dashed line: maximum measurement uncertainity of the power analyzer

The efficiency can now be calculated for different string voltages $u_{\mathrm{G} 1,2}$. This is done with the following equation, where $u_{\mathrm{CH} 1}$ is the measured voltage of channel 1 :

$$
\eta=\frac{p_{\mathrm{out}}}{p_{\text {in }}}=\frac{p_{\mathrm{A}}}{p_{\mathrm{A}}+p_{\mathrm{V}}}=\frac{u_{\mathrm{A}} \cdot i_{\mathrm{A}}}{u_{\mathrm{A}} \cdot i_{\mathrm{A}}+p_{\mathrm{V}}}=\frac{\left(u_{\mathrm{G} 1,2}-u_{\mathrm{CH} 1}\right) \cdot i_{\mathrm{A}}}{\left(u_{\mathrm{G} 1,2}-u_{\mathrm{CH} 1}\right) \cdot i_{\mathrm{A}}+p_{\mathrm{V}}}
$$

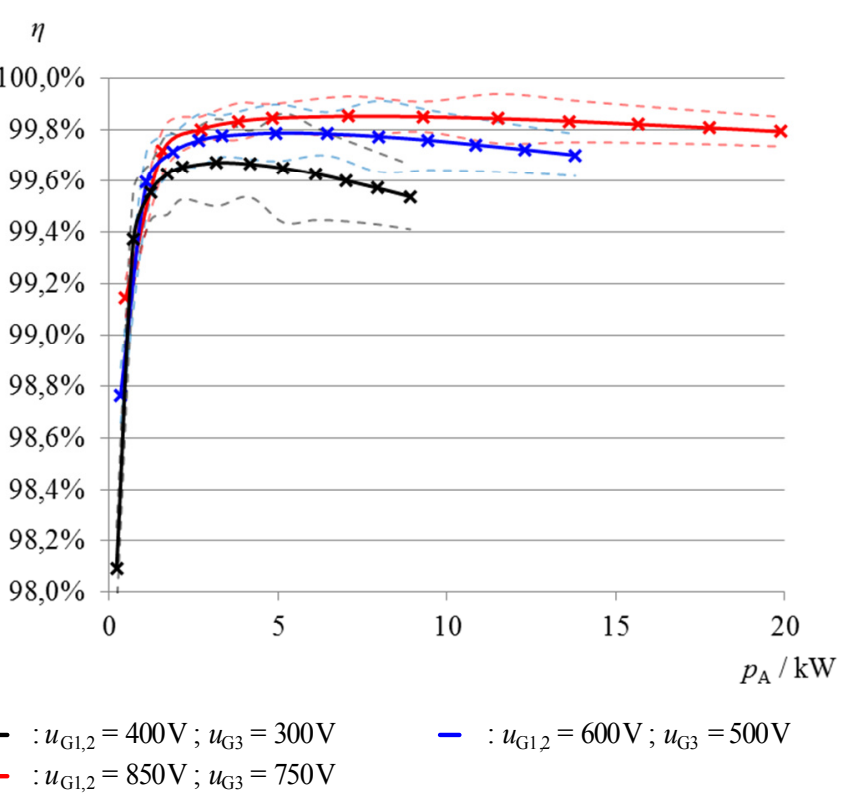

Fig. 15. Calculated efficiency at different string voltages; lines interpolated; dashed line: maximum measurement uncertainity of the power analyzer

The calculated efficiency is shown in Fig. 15. The resulting maximum measurement uncertainty $\Delta \eta$, caused by the power analyzer, is calculated with the total derivative (19) and plotted in dashed lines.

$$
\Delta \eta=\left|\frac{\partial \eta}{\partial p_{\mathrm{V}}}\right| \cdot \Delta p_{\mathrm{V}}+\left|\frac{\partial \eta}{\partial u_{\mathrm{A}}}\right| \cdot \Delta u_{A}+\left|\frac{\partial \eta}{\partial i_{\mathrm{A}}}\right| \cdot \Delta i_{\mathrm{A}}
$$

The efficiency increases with increasing string voltages and reaches a peak value of $99.85 \%$.

\section{CONCLUSION}

An ultra-efficient MPP tracking circuit, that allows the connection of an unlimited number of strings to a solar inverter is described and investigated. All string voltages can be controlled independently. A limited difference between the individual string voltages is usually sufficient for a reasonable operation. This allows the use of transistors with reduced blocking voltages and smaller inductors, which leads to low losses. Furthermore, the circuit can buffer the pulsating energy that occurs when a single-phase inverter is used. A cascaded control scheme is developed and a prototype is built up. The circuit is tested with real photovoltaic panels. Loss measurements are performed and the resulting efficiency is calculated at different operating points. The prototype reaches a maximum efficiency of $99.85 \%$.

\section{REFERENCES}

[1] H. Häberlin, Photovoltaics System Design and Practice: John Wiley \& Sons, Ltd, 2012.

[2] M. Meinhardt, G. Cramer, B. Burger, and P. Zacharias, "Multi-StringConverter with Recuced Specific Costs and Enhanced Functionality," Solar Energy, vol. 69, pp. 217-227, 2001.

[3] S. Poshtkouhi and O. Trescases, "Multi-input single-inductor dc-dc converter for MPPT in parallel-connected photovoltaic applications," in Applied Power Electronics Conference and Exposition (APEC), 2011 Twenty-Sixth Annual IEEE, 2011, pp. 41-47.

[4] A. Khaligh, J. Cao, and Y.-J. Lee, "A Multiple-Input DC-DC Converter Topology," Power Electronics, IEEE Transactions on, vol. 24, pp. 862868, 2009.

[5] N. D. Benavides and P. L. Chapman, "Power budgeting of a multipleinput buck-boost converter," Power Electronics, IEEE Transactions on, vol. 20, pp. 1303-1309, 2005.

[6] M. Gommeringer, A. Schmitt, and J. Kolb, "Schaltungsanordnungen und Verfahren zum Abgreifen elektrischer Leistung von mehreren Modulsträngen", Patent application EP2911284A1, published in 2015.

[7] S. R. McCaslin and B. J. Williams, "Power Shuffling Solar String Equalization System", Patent application US2012/0319489A1, published in 2012.

[8] V. Lo Brano, A. Orioli, G. Ciulla, and A. Di Gangi, "An improved fiveparameter model for photovoltaic modules," Solar Energy Materials \& Solar Cells, vol. 94, pp. 1358-1370, 2010.

[9] D. Graovac, M. Pürschel, and A. Kiep, MOSFET Power Losses Calculation Using the Data-Sheet Parameters: Infineon, 2006.

[10] U. Nuß, Hochdynamische Regelung elektrischer Antriebe: VDE Verlag, 2010.

[11] C. Ackermann, "Optimale Regelung der permanentmagneterregten Synchronmaschine unter Nutzung des Reluktanzmoments," von der Fakultät für Elektrotechnik und Informationstechnik des Karlsruher Instituts für Technologie (KIT) genehmigte Dissertation, 2012.

[12] "ZES Zimmer - User Manual Instrument Family LMG 600," 2014. 